\title{
The Effect of Long-Term Frozen Storage on the Quality of Meat (Longissimus thoracis et Lumborum) from Female Roe Deer (Capreolus capreolus L.)
}

\author{
Tomasz Daszkiewicz $\mathbb{D}$, Dorota Kubiak, and Agata Panfil \\ Department of Commodity Science and Processing of Animal Raw Materials, Faculty of Animal Bioengineering, \\ University of Warmia and Mazury in Olsztyn, Oczapowskiego 5, 10-719 Olsztyn, Poland \\ Correspondence should be addressed to Tomasz Daszkiewicz; tomasz.daszkiewicz@uwm.edu.pl
}

Received 8 May 2018; Revised 23 August 2018; Accepted 1 October 2018; Published 18 October 2018

Academic Editor: Barbara Speranza

Copyright (c) 2018 Tomasz Daszkiewicz et al. This is an open access article distributed under the Creative Commons Attribution License, which permits unrestricted use, distribution, and reproduction in any medium, provided the original work is properly cited.

The objective of this study was to determine the quality of meat (Longissimus thoracis et lumborum) from 10 female roe deer (Capreolus capreolus L.), which was vacuum-packaged, frozen-stored $\left(-26^{\circ} \mathrm{C}\right)$ for 6,10 , and 12 months, and compared with fresh, nonfrozen meat. Roe deer (aged 3 to 5 years) were hunter-harvested in north-eastern Poland in December and January during the same hunting season. Frozen storage did not affect the proximate chemical composition of meat (except for ash content). An analysis of the physicochemical properties of meat revealed that frozen-stored meat was characterized by a darker color, a higher hue angle, lower ability to bind its own and added water, and lower cooking loss compared with nonfrozen meat. The values noted for meat samples that were stored in the freezer for 12 months (increase in $\mathrm{pH}$, considerable decrease in water-holding capacity, and first symptoms of flavor deterioration) indicate that frozen roe deer meat should be stored for no more than 10 to 12 months to maintain its high quality.

\section{Introduction}

There are a number of aspects regarding wild game meat that affects consumer attitudes, such as the following:

(i) Consumers' ethical and moral objections to hunting [1]

(ii) The specific flavor of game meat [2] and consumer concerns regarding its lower tenderness, which are not always justified [3]

(iii) A vanishing tradition of preparing and consuming venison, excluding hunters and their families

(iv) High prices of game meat, relative to poultry meat and pork

(v) Consumer health and safety concerns [4]

(vi) Limited availability of fresh game meat on the market since wild animals are hunted seasonally.
The popularity of game meat is expected to rise because there is a growing interest among consumers in alternative, original, and natural (organic) food products [5]. In order to ensure its continuous supply outside the hunting season, game meat is preserved by freezing. Freezing, frozen storage, and thawing induce undesirable changes in the yield and quality of meat products. However, if the above processes are carried out properly, the observed changes are minor and acceptable to producers, suppliers, and consumers.

The quality of frozen/thawed meat is affected by the amount of frozen and unfrozen water, freezing rate and the temperature and time of frozen storage. The proportion of unfrozen water influences the rate and extent of physical, chemical, and biochemical processes in meat. All the water contained in a food product freezes out at a temperature of $-31^{\circ} \mathrm{C}$ to $-85^{\circ} \mathrm{C}$, whereas in practice, frozen food is usually stored at $-18^{\circ} \mathrm{C}$ to $-23^{\circ} \mathrm{C}[6]$. The optimal temperature for frozen storage of meat is $-55^{\circ} \mathrm{C}$ according to Zhou et al. [7] 
and $-40^{\circ} \mathrm{C}$ according to Leygonie et al. [8]. The freezing rate of water present in meat is correlated with changes in muscle ultrastructure. If the freezing rate is too slow, large, irregularly shaped ice crystals are formed in extracellular spaces and inside muscle fibers [9]. The ice crystals cause damage to the cell membrane and organelles, leading to greater drip loss at thawing and enhanced enzymatic activity [10]. Temperature fluctuations during frozen storage also induce undesirable changes in meat quality due to the activation of recrystallization processes, causing enlargement of ice crystals [11].

Freezing is a preservation method which can considerably slow down but not completely inhibit the processes responsible for quality deterioration of meat during frozen storage. Thus, the recommended storage time for frozen meat should be determined based on the above technological factors as well as the specific properties of a given product and its susceptibility to undesirable changes during storage. Game meat is unique in its harvesting procedure and chemical composition (including a high content of hemeiron and unsaturated phospholipids) which promotes lipid peroxidation $[12,13]$. The aim of this study was to determine the effect of 6-, 10-, and 12-month frozen storage on the quality of roe deer meat.

\section{Materials and Methods}

2.1. Sampling, Freezing, and Thawing. Roe deer (Capreolus capreolus L.) aged 3 to 5 years were hunter-harvested in north-eastern Poland, in December $(n=5)$ and January $(n=5)$ during the same hunting season. The animals were shot (ambush tactics, a heart shot), bled, and eviscerated in the field immediately after shooting. After bleeding and evisceration, the carcasses (including the skin and legs) were transported by hunters (within $2-3 \mathrm{~h}$ of harvest) to a cold store where they were stored at $2-4^{\circ} \mathrm{C}$. Next, they were transported in a refrigerator truck to the meat processing plant where they were stored at $0-2^{\circ} \mathrm{C}$. The carcasses were dressed within $48-54 \mathrm{~h}$ postmortem. During carcass dressing, right Longissimus thoracis et lumborum muscles (LTL) were cut out, packaged in polyethylene bags and transported to the laboratory in a box with ice. Carcasses with signs of bullet damage or evisceration damage to Longissimus muscles and carcasses contaminated with digesta owing to digestive tract damage caused by a bullet or incorrect evisceration were eliminated from the experiment.

Each muscle was divided into four parts of similar weight. Sample I were subjected to analyses immediately after collection. Samples II, III, and IV were vacuumpackaged in barrier bags made of ethylene-vinyl alcohol $(\mathrm{EVOH})$ copolymer, with the use of the PP-5MG (015) vacuum packaging machine (TEPRO SA, Poland). The order in which the samples were allocated to groups I, II, III, and IV was changed for each muscle so as to eliminate the possibility of using only one segment of the muscle in the analyses within a group. Samples II, III, and IV were frozen (freezing rate $>10 \mathrm{~cm} / \mathrm{h}$ ) and stored at $-26^{\circ} \mathrm{C}$ for 6,10 , and 12 months in a freezer with electronic temperature control. The temperature was monitored once daily for five days a week (the temperature remained in the range of -25 to $-26^{\circ} \mathrm{C}$ ). Before analysis, frozen meat samples were thawed for $20 \mathrm{~h}$ at a temperature of $2^{\circ} \mathrm{C}$.

2.2. Research Methods. During a chemical analysis [14], meat samples were assayed for the content of dry matter (by drying at $105^{\circ} \mathrm{C}$ to constant weight), total protein (Kjeldahl method; Kjeltec ${ }^{\mathrm{TM}} 2200$ Auto Distillation Unit; FOSS Analytical, Hilleroed, Denmark), crude fat (Soxhlet method; diethyl ether as the solvent; Soxtec ${ }^{\mathrm{TM}} 2050$ Auto Fat Extraction System, FOSS Analytical, Hilleroed, Denmark), and ash (by incineration at $550^{\circ} \mathrm{C}$ to constant weight).

Meat $\mathrm{pH}$ was measured in water homogenates $(1: 1 \mathrm{~m} / \mathrm{v}$ ratio of meat to redistilled water) using the $340 \mathrm{i} \mathrm{pH}$ meter equipped with the TFK 325 temperature sensor (WTW Wissenschaftlich-Technische Werkstätten, Weilheim, Germany) and the Polilyte Lab electrode (Hamilton Bonaduz AG, Bonaduz, Switzerland).

The parameters of meat color $\left(L^{*}:\right.$ lightness, $a^{*}$ : redness, $b^{*}$ : yellowness, $C^{*}$ : chroma, and $h^{\circ}$ : hue angle) were determined by the CIELAB system [15]. The values of $L^{*}, a^{*}$, and $b^{*}$ were measured with the HunterLab MiniScan XE Plus spectrocolorimeter (Hunter Associates Laboratory, Reston, Virginia, USA) with an illuminant D65, a $10^{\circ}$ standard observer angle, and a $2.54 \mathrm{~cm}$ diameter aperture. The final result was the arithmetic mean of three measurements (made on the surface of muscle cross sections) of each sample. The values of $C^{*}$ and $h^{\circ}$ were calculated from the following formulas: $C^{*}=\left(a^{* 2}+b^{* 2}\right)^{1 / 2}$ and $h^{\circ}=\arctan \left(b^{*} / a^{*}\right)$.

The water-holding capacity of meat was evaluated based on thawing drip loss (the samples were weighed prior to freezing and after thawing at $2^{\circ} \mathrm{C}$ for $20 \mathrm{~h}$; thawing loss was expressed as a percentage of initial weight prior to freezing), natural drip loss and cooking loss [16], forced drip loss by the Grau and Hamm method [17], and the ability to bind added water by the centrifugal method described by Daszkiewicz et al. [18].

The results of the thiobarbituric-acid-reactive substances (TBARS) assay [19] were used to determine the extent of lipid peroxidation. Absorbance was measured with the Specord ${ }^{\circledR} 40$ spectrophotometer (Analytik Jena AG, Jena, Germany) at a wavelength of $532 \mathrm{~nm}$.

Shear force was measured on meat samples prepared as described by Honikel [16], in a Warner-Bratzler head $(500 \mathrm{~N}$, speed $100 \mathrm{~mm} / \mathrm{min})$ attached to the Instron 5542 universal testing machine (Instron, Canton, Massachusetts, USA). The arithmetic means of measurements performed on five cylinder-shaped samples $(1.27 \mathrm{~cm}$ in diameter; $2 \mathrm{~cm}$ in height) cut across the grain were used in a statistical analysis.

Prior to a sensory analysis, meat samples were cooked as described by Daszkiewicz et al. [18]. Meat was cooked in a $0.6 \% \mathrm{NaCl}$ solution (meat to solution weight ratio of $1: 2$ ) at $96 \pm 2{ }^{\circ} \mathrm{C}$. The ultimate temperature inside the sample was $80^{\circ} \mathrm{C}$. The sensory properties of meat (odor, flavor, juiciness, and tenderness) were evaluated by five trained panelists with the use of a 5 -point hedonic scale ( 5 points: most desirable; 1 point: least desirable). Samples $(1 \mathrm{~cm} \times 1 \mathrm{~cm} \times 1 \mathrm{~cm}$ cubes cut 
out in the center of each cooked sample) were cooled to room temperature, encoded, and randomly presented to the panelists. All sensory attributes of the sample were assessed during a single session. The panelists could use redistilled water to clean their mouth between samples.

2.3. Statistical Analysis. The results obtained in the present study were analyzed statistically in the Statistica data analysis software system, version 12 [20], by one-way analysis of variance (ANOVA). The significance of differences between group means was determined by Tukey's test at confidence levels of $P \leq 0.05$ and $P \leq 0.01$.

\section{Results and Discussion}

3.1. Thawing Loss. Meat samples stored for 10 months were characterized by the greatest thawing loss (Table 1), which was $1.31(P \leq 0.01)$ and $0.73(P \leq 0.01)$ percentage points higher compared with samples stored for 6 and 12 months, respectively. In a study by Muela et al. [21], the average thawing loss of lamb meat (Longissimus lumborum) stored for 6 months at $-18^{\circ} \mathrm{C}$ ranged from 2.68 to $3.79 \%$ depending on the freezing method. Vieira et al. [22] reported thawing loss of 3.45 to $3.73 \%$ in samples of Longissimus thoracis collected from the carcasses of bull calves and stored for 30 , 75 , and 90 days at $-20^{\circ} \mathrm{C}$ and $-80^{\circ} \mathrm{C}$. A direct comparison of our findings with the results of published studies is difficult due to certain methodological differences in thawing conditions (different temperature and time of thawing, thawing of packaged or unpackaged meat, different final internal temperature) and the formulas used to calculate the thawing loss. According to some researchers, the weight of a thawed meat sample should be compared with the weight of the sample before freezing. In this approach, the final result encompasses not only weight loss due to drip loss during thawing but also previous weight losses related to packaging and storage.

The increase in thawing drip loss with prolonged storage, observed in our study, was related to a decrease in the waterholding capacity of meat. Ice crystals formed during freezing interact with cell structures; water migrates from the intracellular space to the extracellular space, and the concentration of intracellular fluid increases. In the extracellular space, water freezes out and ice crystals enlarge which exacerbates their destructive effect on muscle ultrastructure. The increase in the concentrations of water-soluble compounds in the cell leads to denaturation of water-binding proteins [23]. The above processes affect thawing drip loss, which is reflected in meat weight loss and changes in the chemical composition and other properties of meat which are linked with its water content.

3.2. Proximate Chemical Composition. An analysis of the proximate chemical composition of roe deer meat revealed significant differences between the analyzed samples only in ash content (Table 1). Fresh meat had higher ash content $(P \leq 0.01)$ than frozen/thawed meat. The ash content of meat decreased with prolonged frozen storage.
The decrease in mineral content noted in thawed meat was probably related to thawing drip loss. A decrease in the concentrations of water-soluble compounds (proteins, carbohydrates, minerals, and vitamins) is a natural consequence of meat thawing [24]. The results of studies investigating the influence of frozen storage time on the concentrations of water-soluble compounds and dry matter in meat may be inconclusive due to the combined effect of water loss and the loss of water-soluble compounds [25, 26]. Theoretically, drip loss should be accompanied by an increase in the concentrations of dry matter components. However, this effect is "masked" by the simultaneous loss of water-soluble compounds. It should also be noted that the differences in the proximate chemical composition of meat samples before and after frozen storage could result from natural variations in the chemical composition of LTL muscles. Other important considerations are the reproducibility, repeatability, and precision of analytical procedures and methods.

3.3. $p H$ Value. Meat samples stored for 12 months were characterized by the highest $\mathrm{pH}$ (Table 2 ), which was significantly $(P \leq 0.01)$ higher than the average values noted in the remaining samples of frozen/thawed meat and in fresh meat samples. However, the differences between the means in groups were minor (the highest difference reached 0.07 units), and their statistical significance reflected low variation in the measured values. According to Leygonie et al. [8], the $\mathrm{pH}$ of frozen/thawed meat is usually lower than the $\mathrm{pH}$ of fresh meat. This may be due to the denaturation of protein buffer systems, release of hydrogen ions, and increased concentrations of water-soluble compounds in meat in consequence of drip loss during thawing as well as the release of hydrogen atoms following protein deamination by microorganisms and enzymes. However, the cited authors stressed that the lower $\mathrm{pH}$ of thawed meat is not observed in all cases. Farouk and Freke [27] did not find significant changes in the $\mathrm{pH}$ of red deer meat during 9-month frozen storage. Daszkiewicz et al. [28] also reported that fresh and freezer-stored (10 months) fallow deer meat was characterized by similar average $\mathrm{pH}$ values (5.53 and 5.58, respectively). Ablikim et al. [26] demonstrated that changes (both increase and decrease) in the $\mathrm{pH}$ of lamb meat during 30 -day frozen storage at $-18^{\circ} \mathrm{C}$ were correlated with the animals' breed and the analyzed muscle.

3.4. TBARS Value. Average TBARS values (Table 2) were high in both fresh and frozen/thawed meat samples. They remained relatively stable $(P>0.05)$ throughout frozen storage and did not differ significantly $(P>0.05)$ from the TBARS values of fresh meat. The high TBARS values of roe deer meat could be expected based on previous research which revealed a high content of unsaturated phospholipids in game meat [13] and pro-oxidant iron ions in myoglobin [12]. The susceptibility of game meat to oxidation was reported by Okabe et al. [29] in whose study, the malondialdehyde content of fresh sika deer meat was up to $6 \mathrm{mg} / \mathrm{kg}$. In our study, meat samples were vacuum-packaged 
TABle 1: Thawing drip loss and chemical composition of meat (Longissimus thoracis et lumborum) from female roe deer before and after frozen storage (arithmetic mean $\pm \mathrm{SD}$ ).

\begin{tabular}{|c|c|c|c|c|}
\hline \multirow{2}{*}{ Parameter } & \multicolumn{4}{|c|}{ Frozen storage time (months) } \\
\hline & $0(n=10)$ & $6(n=10)$ & $10(n=10)$ & $12(n=10)$ \\
\hline Thawing loss (\%) & - & $0.85 \pm 0.20^{\mathrm{A}}$ & $2.16 \pm 0.90^{\mathrm{Ba}}$ & $1.43 \pm 0.79^{\mathrm{b}}$ \\
\hline Dry matter (g/kg) & $260.87 \pm 6.43$ & $258.21 \pm 7.40$ & $259.93 \pm 7.58$ & $257.75 \pm 5.18$ \\
\hline Total protein $(\mathrm{g} / \mathrm{kg})$ & $229.76 \pm 8.24$ & $228.30 \pm 3.92$ & $232.50 \pm 5.19$ & $229.50 \pm 3.84$ \\
\hline Fat $(\mathrm{g} / \mathrm{kg})$ & $10.25 \pm 4.94$ & $9.41 \pm 6.45$ & $8.16 \pm 4.42$ & $10.25 \pm 6.23$ \\
\hline Ash $(\mathrm{g} / \mathrm{kg})$ & $11.53 \pm 0.40^{\mathrm{A}}$ & $10.79 \pm 0.43^{\mathrm{B}}$ & $10.06 \pm 0.37^{\mathrm{C}}$ & $9.82 \pm 0.79^{\mathrm{C}}$ \\
\hline $\begin{array}{l}\text { The ratio between total } N \text { of water-soluble protein } \\
\text { compounds and total } N \text { in meat (\%) }\end{array}$ & $28.97 \pm 1.67$ & $29.74 \pm 1.30$ & - & $29.15 \pm 1.58$ \\
\hline $\begin{array}{l}\text { The ratio between } N \text { of water-soluble nonprotein } \\
\text { compounds and total } N \text { in meat }(\%)\end{array}$ & $13.53 \pm 0.76$ & $14.64 \pm 0.92$ & - & $14.46 \pm 0.82$ \\
\hline Water/protein ratio & $3.22 \pm 0.12$ & $3.25 \pm 0.08$ & $3.18 \pm 0.09$ & $3.24 \pm 0.06$ \\
\hline
\end{tabular}

TABLE 2: $\mathrm{pH}$ and TBARS values (mg malondialdehyde/kg meat) of meat (Longissimus thoracis et lumborum) from female roe deer before and after frozen storage (arithmetic mean $\pm \mathrm{SD}$ ).

\begin{tabular}{lcccc}
\hline \multirow{2}{*}{ Parameter } & \multicolumn{5}{c}{ Frozen storage time (months) } \\
& $0(n=10)$ & $6(n=10)$ & $10(n=10)$ & $12(n=10)$ \\
\hline \multirow{2}{*}{ pH } & $5.52 \pm$ & $5.53 \pm$ & $5.54 \pm$ & $5.59 \pm$ \\
TBARS & $0.04^{\mathrm{A}}$ & $0.03^{\mathrm{A}}$ & $0.04^{\mathrm{A}}$ & $0.05^{\mathrm{B}}$ \\
value & $0.92 \pm 0.11$ & $0.91 \pm 0.08$ & $0.98 \pm 0.12$ & $0.98 \pm 0.09$ \\
$\begin{array}{l}\text { A,B } \text { Values within a row with different superscript letters are significantly } \\
\text { different at } P \leq 0.01 .\end{array}$
\end{tabular}

before freezing, which could contribute to an absence of changes in TBARS values during storage. This is consistent with the findings of Daszkiewicz et al. [28] who demonstrated that storage in the freezer had no significant influence on TBARS values in vacuum-packaged fallow deer meat. Farouk and Freke [27] also reported that malondialdehyde concentration was lower in samples of red deer meat which were vacuum-packaged and stored in the freezer than in samples that were not vacuum-packaged (the latter were placed in bags of the same type as those used for vacuum packaging, except that the seals were broken to permit free exchange of air between the inside and outside of the packaging). While interpreting the malondialdehyde content of meat samples during storage, it should be noted that malondialdehyde is characterized by low stability in biological samples due to its high tendency to react with proteins and amino acids [30] and susceptibility to rapid enzymatic degradation [31]. These processes lead to the formation of compounds that are not determined in the TBARS assay.

3.5. Meat Color. Meat samples that were stored in the freezer for 6,10 , and 12 months had a darker color (lower $L^{*}$ ) than fresh meat (differences significant at $P \leq 0.05$ and $P \leq 0.01$ ) (Table 3 ). The time of frozen storage had no influence $(P>0.05)$ on the values of parameter $L^{*}$. The values of parameters $a^{*}, b^{*}$, and $C^{*}$ were similar $(P>0.05)$ in samples of fresh meat and meat stored for different periods of time
TABlE 3: Color parameters of meat (Longissimus thoracis et lumborum) from female roe deer before and after frozen storage (arithmetic mean $\pm \mathrm{SD}$ ).

\begin{tabular}{lcccc}
\hline \multirow{2}{*}{ Parameter } & \multicolumn{4}{c}{ Frozen storage time (months) } \\
& $0(n=10)$ & $6(n=10)$ & $10(n=10)$ & $12(n=10)$ \\
\hline \multirow{2}{*}{$L^{*}$} & $32.98 \pm$ & $31.83 \pm$ & $31.23 \pm$ & $31.39 \pm$ \\
& $1.30^{\mathrm{Aa}}$ & $0.92^{\mathrm{b}}$ & $0.96^{\mathrm{B}}$ & $1.02^{\mathrm{B}}$ \\
$a^{*}$ & $15.17 \pm 1.01$ & $14.59 \pm 0.98$ & $14.04 \pm$ & $14.23 \pm$ \\
& & & 1.21 & 1.50 \\
$b^{*}$ & $11.20 \pm 0.96$ & $11.11 \pm 0.56$ & $11.05 \pm$ & $11.11 \pm$ \\
& & & 0.76 & 0.82 \\
$C^{*}$ & $18.86 \pm 1.32$ & $18.35 \pm 1.04$ & $17.88 \pm$ & $18.06 \pm$ \\
& & $37.33 \pm$ & $38.26 \pm$ & $38.06 \pm$ \\
$h^{\circ}$ & $36.43 \pm 1.56^{\mathrm{a}}$ & $1.39^{\mathrm{ab}}$ & $1.90^{\mathrm{b}}$ & $1.82^{\mathrm{b}}$ \\
& & &
\end{tabular}

$\overline{\mathrm{A}, \mathrm{B}}$ Values within a row with different superscript letters are significantly different at $P \leq 0.01$. ${ }^{\text {a,b }}$ Values within a row with different superscript lowercase letters are significantly different at $P \leq 0.05$.

(Table 3). However, thawed meat tended to have a lower contribution of redness $\left(a^{*}\right)$ and, consequently, the values of the hue angle $\left(h^{\circ}\right)$ were higher $(P \leq 0.05)$ in meat stored for 10 and 12 months compared with fresh meat (Table 3).

Changes in the color of meat during freezing, frozen storage, and thawing are determined by several factors. The above processes may be accompanied by denaturation of globins found in the muscle pigment, which makes myoglobin more susceptible to auto-oxidation [8]. The activity of metmyoglobin-reducing enzymes is also lower in frozen meat [32]. Lipid degradation products decrease the redox stability of oxymyoglobin and the probability of enzymatic reduction of metmyoglobin to myoglobin [33]. Changes in the color of frozen/thawed meat may also result from physical processes related to changes in the concentrations of compounds in the surface layer due to water freezing, thawing drip loss, and drying. Changes in color, including darkening, caused by the accumulation of metmyoglobin are frequently observed in frozen/thawed meat [22, 23, 34].

In the present study, the relatively small differences between the average values of $a^{*}, b^{*}, C^{*}$, and $h^{\circ}$ in frozen/thawed meat relative to fresh meat, and their minor 
changes during frozen storage, could also be attributed to vacuum packaging. Most probably, vacuum packaging limited the oxidation of pigments and lipids, as indicated by TBARS values. Similar observations were made by other authors. Farouk and Freke [27] demonstrated that vacuumpackaged and frozen-stored samples of red deer meat were characterized by more desirable color parameters (higher values of $a^{*}$ and $C^{*}$ and lower values of $h^{\circ}$ ) than samples that were not vacuum-packaged. Lanari et al. [35] reported higher color stability (lower concentration of metmyoglobin) of vacuum-packaged and frozen-stored beef samples compared with samples packaged in polyethylene. Daszkiewicz et al. [28] observed greater changes (decrease in $a^{*}$, $b^{*}$, and $C^{*}$ values) in the color of thawed game meat, in comparison with those noted in the present study.

3.6. Water-Holding Capacity. The water-holding capacity of roe deer meat, presented in Table 4 , should be analyzed in relation to the thawing loss data shown in Table 1 . Thawed meat was characterized by greater natural drip loss than fresh meat (Table 4). The difference between means in groups was somewhat smaller only in samples stored for 10 months $(P>0.05)$. An analysis of the water-holding capacity of fresh and frozen/thawed meat, performed using the Grau and Hamm method (Table 4), revealed no significant $(P>0.05)$ differences between mean values in groups, but frozen/thawed meat tended to have a lower water-holding capacity (excluding samples stored for 10 months). The higher water-holding capacity of meat samples stored for 10 months could be attributed to the fact that they had slightly lower water content (greater thawing drip loss) and a higher content of proteins that could bind water. An evaluation of the water-holding capacity of meat based on natural drip loss and an analysis performed using the Grau and Hamm method produced surprising results in samples stored for 6 months (Table 4 ) which were able to bind more added water compared with meat stored for 10 and 12 months $(P \leq 0.01)$ and fresh meat $(P>0.05)$. The only logical explanation is that meat stored for 6 months had slightly higher $(P>0.05)$ concentrations of water-soluble nitrogen compounds, including water-binding proteins. An increase in the content of water-soluble sarcoplasmic proteins in red deer meat during 6-month frozen storage was also observed by Farouk and Freke [27]. An increase in protein solubility in beef during frozen storage was reported by Farouk and Wieliczko [36] and Zhang et al. [37].

Frozen/thawed meat was characterized by lower $(P \leq 0.01)$ cooking loss than fresh meat (Table 4$)$. Frozen storage time had no significant $(P>0.05)$ influence on cooking loss, which however tended to be lower in thawed meat that was stored for 10 months. Meat samples stored for 10 months had also lower natural drip loss and forced drip loss (determined by the Grau and Hamm method), and these parameters are linked with cooking loss. An analysis of cooking loss is more complex because there are several factors involved. The amount of cooking loss is mostly determined by denaturation of muscle proteins and the degree of fragmentation and rupture of myofibrils [38].
Cooking drip is composed of constitutive water and water that is released from melting fat and denatured proteins under exposure to heat [22]. As already mentioned, cooking loss is also influenced by the volume of thawing loss. The results of a cooking loss analysis in samples of fresh and frozen/thawed meat are inconclusive. In a study by Vieira et al. [22], frozen-stored beef samples were characterized by greater cooking loss $(P \leq 0.01)$ than fresh samples, whereas the differences between frozen samples stored for different periods of time were not significant. Daszkiewicz et al. [28] observed greater cooking loss in thawed fallow deer meat than in fresh meat. High positive coefficients of correlation $(0.966, P \leq 0.01)$ between frozen storage time and cooking loss in lamb meat samples were noted by Ablikim et al. [26]. In contrast, Muela et al. [21] and Leygonie et al. [23] did not find significant differences in the cooking loss of fresh and frozen lamb and ostrich meat, respectively.

3.7. Shear Force and Sensory Evaluation. A sensory evaluation revealed that the analyzed roe deer meat was characterized by very high quality (Table 5). Juiciness and odor intensity were the only sensory attributes that received somewhat lower scores. However, a less intensive odor could be considered desirable because not all consumers accept the characteristic flavor of game meat. In comparison with frozen/thawed meat, fresh meat received higher average scores $(P \leq 0.01)$ only for juiciness. No significant $(P>0.05)$ changes in the analyzed sensory parameters and shear force values were noted during frozen storage (Table 5). Flavor desirability was the only parameter that received lower scores after 12 -month storage (the greatest difference was found relative to meat stored for 10 months: $P \leq 0.05)$.

One of the common problems encountered during meat storage is the development of undesirable flavor characteristics due to oxidative changes [39]. As already mentioned, those changes are slowed down by vacuum packaging, but they cannot be completely eliminated. It appears that the adverse effects of oxidation could contribute to slightly lower scores $(P>0.05)$ for the flavor desirability of meat stored for 12 months in our experiment.

The lower juiciness of frozen stored meat most likely resulted from the loss of water during thawing and cooking loss which was only slightly lower (from 1.99 to 2.85 percentage points) relative to fresh meat, although the noted difference was statistically significant $(P \leq 0.01)$. A negative correlation between meat juiciness and cooking loss was also reported by other authors, including Aaslyng et al. [40] and Jung et al. [41]. Daszkiewicz et al. [28] demonstrated that thawed fallow deer meat was less juicy than fresh meat.

According to Leygonie et al. [8], frozen/thawed meat is more tender than unfrozen meat, unless meat is aged prior to being frozen. This is consistent with the findings of other authors who investigated game meat [28]. Adequate tenderness of frozen meat is the outcome of autolysis of muscle fibers during meat aging before freezing and the loss of 
TABle 4: Water-holding capacity of meat (Longissimus thoracis et lumborum) from female roe deer before and after frozen storage (arithmetic mean $\pm \mathrm{SD}$ ).

\begin{tabular}{|c|c|c|c|c|}
\hline \multirow{2}{*}{ Parameter } & \multicolumn{4}{|c|}{ Frozen storage time (months) } \\
\hline & $0(n=10)$ & $6(n=10)$ & $10(n=10)$ & $12(n=10)$ \\
\hline Drip losses (\%) & $2.79 \pm 0.71^{\mathrm{A}}$ & $4.70 \pm 1.54^{\mathrm{BCa}}$ & $3.39 \pm 0.95^{\mathrm{ABb}}$ & $5.76 \pm 1.53^{\mathrm{C}}$ \\
\hline Cooking loss (\%) & $31.99 \pm 1.20^{\mathrm{A}}$ & $30.01 \pm 1.58^{\mathrm{B}}$ & $29.14 \pm 1.57^{\mathrm{B}}$ & $29.33 \pm 1.63^{\mathrm{B}}$ \\
\hline $\begin{array}{l}\text { Water-holding capacity-Grau and Hamm method } \\
\left(\mathrm{cm}^{2}\right)\end{array}$ & $3.42 \pm 0.81$ & $4.12 \pm 0.54$ & $3.50 \pm 0.91$ & $4.19 \pm 1.00$ \\
\hline Water-binding capacity- centrifugal method (\%) & $30.46 \pm 6.17^{\mathrm{ABa}}$ & $32.23 \pm 3.90^{\mathrm{A}}$ & $24.66 \pm 4.78^{\mathrm{Bb}}$ & $17.94 \pm 4.18^{\mathrm{C}}$ \\
\hline
\end{tabular}

$\overline{\mathrm{A}, \mathrm{B}, \mathrm{C}}$ Values within a row with different superscript letters are significantly different at $P \leq 0.01{ }^{\mathrm{a}, \mathrm{b}}$ Values within a row with different superscript lowercase letters are significantly different at $P \leq 0.05$.

TABle 5: Sensory properties (points) and shear force (Newton) values of meat (Longissimus thoracis et lumborum) from female roe deer before and after frozen storage (arithmetic mean $\pm \mathrm{SD}$ ).

\begin{tabular}{lcccc}
\hline \multirow{2}{*}{ Parameter } & \multicolumn{3}{c}{ Frozen storage time (months) } \\
& $0(n=10)$ & $6(n=10)$ & $10(n=10)$ & $12(n=10)$ \\
\hline Odor: intensity & $4.05 \pm 0.64$ & $3.85 \pm 0.58$ & $3.85 \pm 0.47$ & $3.95 \pm 0.72$ \\
Odor: desirability & $5.00 \pm 0.00$ & $5.00 \pm 0.00$ & $4.95 \pm 0.16$ & $4.05 \pm 0.16$ \\
Flavor: intensity & $4.50 \pm 0.58$ & $4.10 \pm 0.32$ & $5.00 \pm 0.00^{\mathrm{a}}$ & $4.20 \pm 0.71$ \\
Flavor: desirability & $4.75 \pm 0.42^{\mathrm{ab}}$ & $4.80 \pm 0.42^{\mathrm{ab}}$ & $3.35 \pm 0.41^{\mathrm{B}}$ & $4.55 \pm 0.44^{\mathrm{b}}$ \\
Juiciness & $3.95 \pm 0.28^{\mathrm{A}}$ & $3.20 \pm 0.42^{\mathrm{B}}$ & $5.00 \pm 0.00$ & $3.20 \pm 0.42^{\mathrm{B}}$ \\
Tenderness & $4.75 \pm 0.42$ & $5.00 \pm 0.00$ & $15.81 \pm 2.06$ & $4.85 \pm 0.34$ \\
Shear force value & $17.77 \pm 3.07$ & $16.13 \pm 1.02$ & $16.63 \pm 2.19$ \\
\hline
\end{tabular}

$\overline{\mathrm{A}, \mathrm{B}}$ Values within a row with different superscript letters are significantly different at $P \leq 0.01$. $^{\mathrm{a}, \mathrm{b}}$ Values within a row with different superscript lowercase letters are significantly different at $P \leq 0.05$.

structural integrity of muscle fibers caused by ice crystals formed during freezing [23]. In the present study, no significant differences were found in tenderness or shear force values between fresh and frozen roe deer meat. Frozen storage time had no effect on the above parameters because fresh meat was characterized by desirable tenderness and shear force values. Good tenderness of meat from some Cervidae has been explained by the increased activity of proteolytic enzymes (calpains and cathepsins) and the small muscle fiber diameter [42].

\section{Conclusions}

Vacuum packaging combined with frozen storage effectively protected roe deer meat against oxidative changes and reduced the negative effects of oxidation on the color and sensory properties of meat. The values noted for meat samples that were stored in the freezer for 12 months (increase in $\mathrm{pH}$, considerable decrease in water-holding capacity, and first symptoms of flavor deterioration) indicate that frozen roe deer meat should be stored for no more than 10 to 12 months to maintain its high quality.

\section{Data Availability}

The data used to support the findings of this study are available from the corresponding author upon request.

\section{Conflicts of Interest}

The authors wish to confirm that no known conflicts of interest are associated with the publication of this manuscript.

\section{References}

[1] P. E. Ljung, S. J. Riley, T. A. Heberlein, and G. Ericsson, "Eat prey and love: game-meat consumption and attitudes toward hunting," Wildlife Society Bulletin, vol. 36, no. 4, pp. 669-675, 2012.

[2] E. Wiklund, T. R. Manley, R. P. Littlejohn, and J. M. Stevenson-Barry, "Fatty acid composition and sensory quality of Musculus longissimus and carcass parameters in red deer (Cervus elaphus) grazed on natural pasture or fed a commercial feed mixture," Journal of the Science of Food and Agriculture, vol. 83, no. 5, pp. 419-424, 2003.

[3] J. Nagy, G. Bázár, P. Horn et al., "Investigating venison sausages by means of human sensory panel and electronic nose," Acta Agraria Kaposváriensis, vol. 18, no. 1, pp. 76-86, 2014.

[4] K. Kwiecińska, M. Kosicka-Gębska, J. Gębski, and K. Gutkowska, "Prediction of the conditions for the consumption of game by Polish consumers," Meat Science, vol. 131, pp. 28-33, 2017.

[5] L. C. Hoffman and E. Wiklund, "Game and venison-meat for the modern consumer," Meat Science, vol. 74, no. 1, pp. 197-208, 2006.

[6] S. Estrada-Flores, "Transportation of frozen foods," in Handbook of Frozen Food Processing and Packaging, D.-W. Sun, Ed., p. 219, 2nd edition, CRC Press Taylor \& Francis Group, Boca Raton, FL, USA 2nd edition, 2011.

[7] G. H. Zhou, X. L. Xu, and Y. Liu, "Preservation technologies for fresh meat-a review," Meat Science, vol. 86, no. 1, pp. 119-128, 2010.

[8] C. Leygonie, T. J. Britz, and L. C. Hoffman, "Impact of freezing and thawing on the quality of meat: review," Meat Science, vol. 91, no. 2, pp. 93-98, 2012.

[9] X. L. Yu, X. B. Li, L. Zhao et al., "Effects of different freezing rates and thawing rates on the manufacturing properties and structure of pork," Journal of Muscle Foods, vol. 21, no. 2, pp. 177-196, 2010. 
[10] Y.-S. Choi, S.-K. Ku, J.-Y. Jeong, K.-H. Jeon, and Y.-B. Kim, "Changes in ultrastructure and sensory characteristics on electromagnetic and air blast freezing of beef during frozen storage," Korean Journal for Food Science of Animal Resources, vol. 35, no. 1, pp. 27-34, 2015.

[11] A. E. Bevilacqua and N. E. Zaritzky, "Ice recrystallization in frozen beef," Journal of Food Science, vol. 47, no. 5, pp. 1410-1414, 1982.

[12] E. Wiklund, S. Sampels, T. R. Manley, J. Pickova, and R. P. Littlejohn, "Effects of feeding regimen and chilled storage on water-holding capacity, colour stability, pigment content and oxidation in red deer (Cervus elaphus) meat," Journal of the Science of Food and Agriculture, vol. 86, no. 1, pp. 98-106, 2006.

[13] J. Neethling, L. C. Hoffman, and M. Muller, "Factors influencing the flavour of game meat: a review," Meat Science, vol. 113, pp. 139-153, 2016.

[14] Association of Official Analytical Chemists (AOAC), Official Methods of Analysis of the Association of Official Analytical Chemists, Association of Official Analytical Chemists, Washington, DC, USA, 15th edition, 1990.

[15] Commission Internationale de l'Eclairage (CIE), Recommendations on Uniform Color Spaces-Color Difference Equations. Psychometric Color Terms. Supplement No. 2 to CIE Publication No. 15 (E-1.3.1.) 1978, 1971/(TC-1-3), Commission Internationale de l'Eclairage, Paris, France, 1978.

[16] K. O. Honikel, "Reference methods supported by OECD and their use in Mediterranean meat products," Food Chemistry, vol. 59, no. 4, pp. 573-582, 1997.

[17] M. J. Van Oeckel, N. Warnants, and C. V. Boucqueé, “Comparison of different methods for measuring water holding capacity and juiciness of pork versus on-line screening methods," Meat Science, vol. 51, no. 4, pp. 313-320, 1999.

[18] T. Daszkiewicz, P. Janiszewski, and S. Wajda, "Quality characteristics of meat from wild red deer (Cervus elaphus L.) hinds and stags," Journal of Muscle Foods, vol. 20, no. 4, pp. 428-448, 2009.

[19] J. Pikul, D. E. Leszczyński, and F. A. Kummerow, "Evaluation of three modified TBA methods for measuring lipid oxidation in chicken meat," Journal of Agricultural and Food Chemistry, vol. 37, no. 5, pp. 1309-1313, 1989.

[20] StatSoft, Inc., STATISTICA (Data Analysis Software System), Version 12, StatSoft, Inc., Tulsa, OK, USA, 2014, http://www. statsoft.com.

[21] E. Muela, C. Sañudo, M. M. Campo, I. Medel, and J. A. Beltrán, "Effect of freezing method and frozen storage duration on instrumental quality of lamb throughout display," Meat Science, vol. 84, no. 4, pp. 662-669, 2010.

[22] C. Vieira, M. T. Diaz, B. Martínez, and M. D. García-Cachán, "Effect of frozen storage conditions (temperature and length of storage) on microbiological and sensory quality of rustic crossbred beef at different states of ageing," Meat Science, vol. 83, no. 3, pp. 398-404, 2009.

[23] C. Leygonie, T. J. Britz, and L. C. Hoffman, "Meat quality comparison between fresh and frozen/thawed ostrich $M$. iliofibularis," Meat Science, vol. 91, no. 3, pp. 364-368, 2012.

[24] A. Sehar, M. I. Khan, and F. Faiz, "Effect of thawing on frozen meat quality: a comprehensive review," Pakistan Journal of Food Sciences, vol. 23, no. 4, pp. 198-211, 2013.

[25] A. W. J. Savage, P. D. Warris, and P. D. Jolley, "The amount and composition of the proteins in drip from stored pig meat," Meat Science, vol. 27, no. 4, pp. 289-303, 1990.
[26] B. Ablikim, Y. Liu, A. Kerim, P. Shen, P. Abdurerim, and G. H. Zhou, "Effects of breed, muscle type, and frozen storage on physico-chemical characteristics of lamb meat and its relationship with tenderness," CyTA-Journal of Food, vol. 14, no. 1, pp. 109-116, 2016.

[27] M. M. Farouk and C. Freke, "Packaging and storage effects on the functional properties of frozen venison," Journal of Muscle Foods, vol. 19, no. 3, pp. 275-287, 2008.

[28] T. Daszkiewicz, T. Lipowski, and D. Kubiak, "Effect of freezer storage on quality of $M$. longissimus lumborum from fallow deer (Dama dama L.)," South African Journal of Animal Science, vol. 47, no. 6, pp. 834-841, 2017.

[29] Y. Okabe, A. Watanabe, H. Shingu et al., "Effects of atocopherol level in raw venison on lipid oxidation and volatiles during storage," Meat Science, vol. 62, no. 4, pp. 457-462, 2002.

[30] B. C. Shin, J. H. Huggins, and K. L. Carrawa, "Effects of pH, concentration and aging on the malondialdehyde reaction with proteins," Lipids, vol. 7, no. 4, pp. 229-233, 1972.

[31] G. M. Siu and H. H. Draper, "Metabolism of malondialdehyde in vivo and in vitro," Lipids, vol. 17, no. 5, pp. 349-355, 1982.

[32] M. B. Abdallah, J. A. Marchello, and H. A. Ahmad, "Effect of freezing and microbial growth on myoglobin derivatives of beef," Journal of Agricultural and Food Chemistry, vol. 47, no. 10, pp. 4093-4099, 1999.

[33] S. Lee, A. L. Phillips, D. C. Liebler, and C. Faustman, "Porcine oxymyoglobin and lipid oxidation in vitro," Meat Science, vol. 63, no. 2, pp. 241-247, 2003.

[34] K.-I. Kim, J.-B. Shim, S.-M. Yoo et al., "Effects of various freezing and thawing techniques on pork quality in ready-toeat meals," African Journal of Food Science, vol. 9, no. 11, pp. 525-533, 2015.

[35] M. C. Lanari, A. E. Bevilacqua, and N. E. Zaritzky, "Pigments modifications during freezing and frozen storage of packaged beef," Journal of Food Process Engineering, vol. 12, no. 1, pp. 49-66, 1990.

[36] M. M. Farouk and K. J. Wieliczko, "Effect of diet and fat content on the functional properties of thawed beef," Meat Science, vol. 64, no. 4, pp. 451-458, 2003.

[37] S. X. Zhang, M. M. Farouk, O. A. Young, K. J. Wieliczko, and C. Podmore, "Functional stability of frozen normal and high pH beef,” Meat Science, vol. 69, no. 4, pp. 765-772, 2005.

[38] B. W. Berry, G. C. Smith, J. V. Spencer, and G. H. Kroening, "Effects of freezing method, length of frozen storage and cookery from the thawed or frozen state on palatability characteristics of pork," Journal of Animal Science, vol. 32, no. 4, pp. 636-640, 1971.

[39] J. Kanner, "Oxidative processes in meat and meat products: quality implications," Meat Science, vol. 36, no. 1-2, pp. 169-189, 1994.

[40] M. D. Aaslyng, C. Bejerholm, P. Ertbjerg, H. C. Bertram, and H. J. Andersen, "Cooking loss and juiciness of pork in relation to raw meat quality and cooking procedure," Food Quality and Preference, vol. 14, no. 4, pp. 277-288, 2003.

[41] E.-Y. Jung, Y.-H. Hwang, and S.-T. Joo, "The relationship between chemical compositions, meat quality, and palatability of the 10 primal cuts from Hanwoo steer," Korean Journal for Food Science of Animal Resources, vol. 36, no. 2, pp. 145-151, 2016.

[42] R. G. Taylor, R. Labas, F. J. M. Smulders, and E. Wiklund, "Ultrastructural changes during aging in M. longissimus thoracis from moose and reindeer," Meat Science, vol. 60, no. 4, pp. 321-326, 2002. 


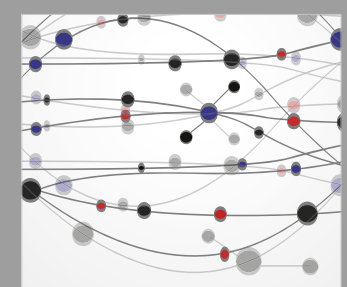

The Scientific World Journal
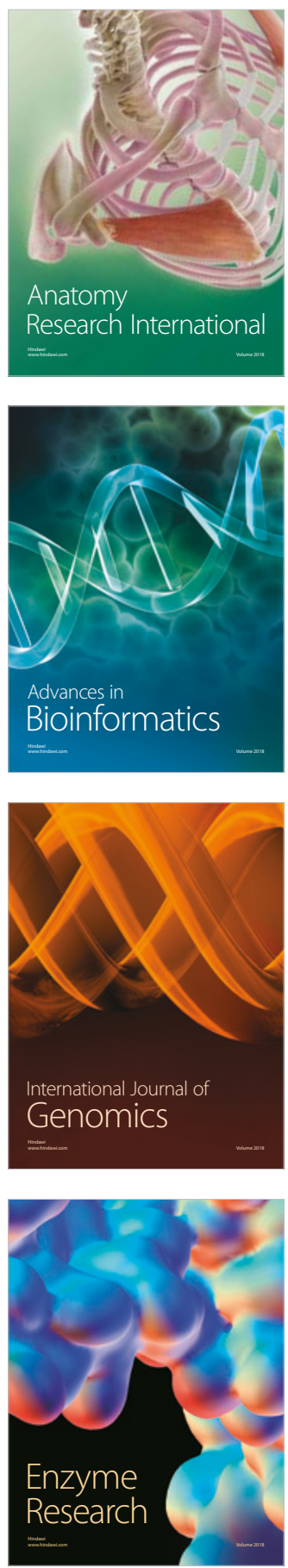
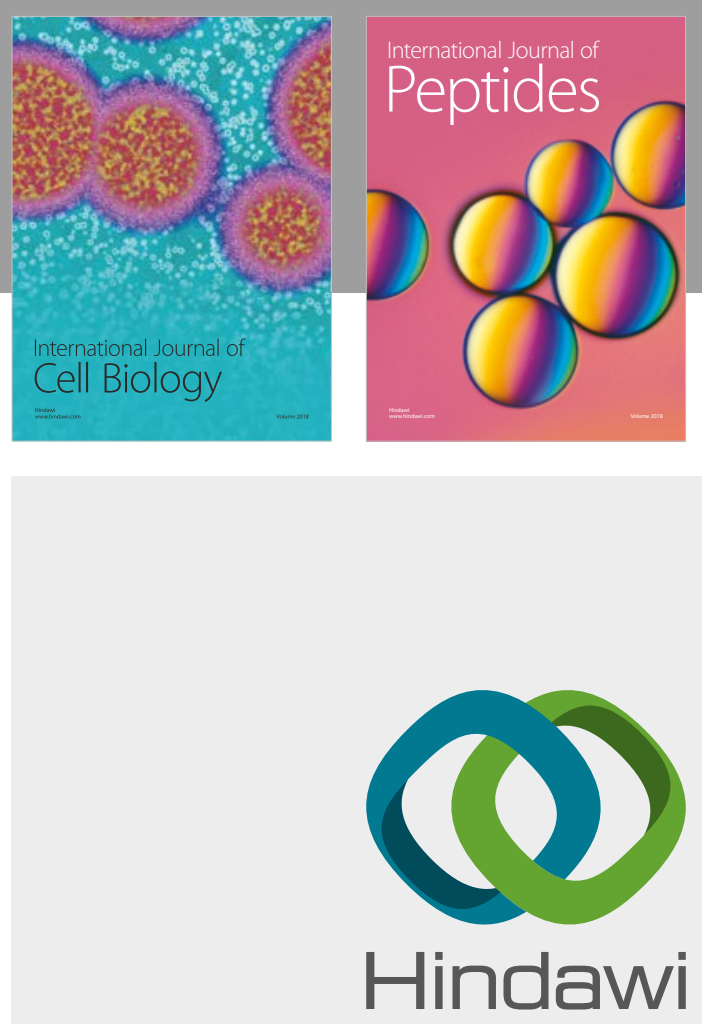

Submit your manuscripts at

www.hindawi.com
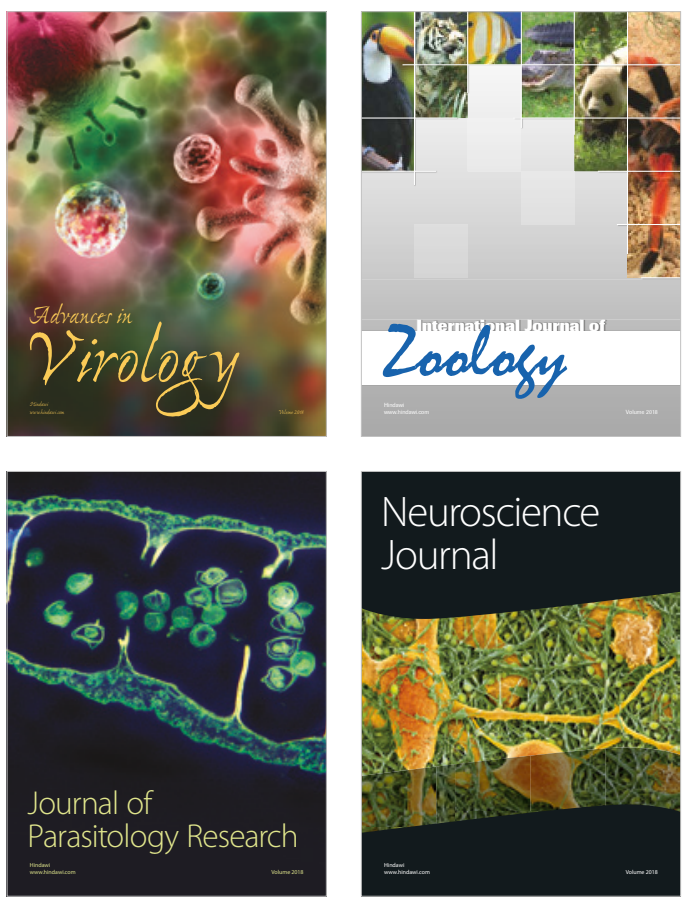
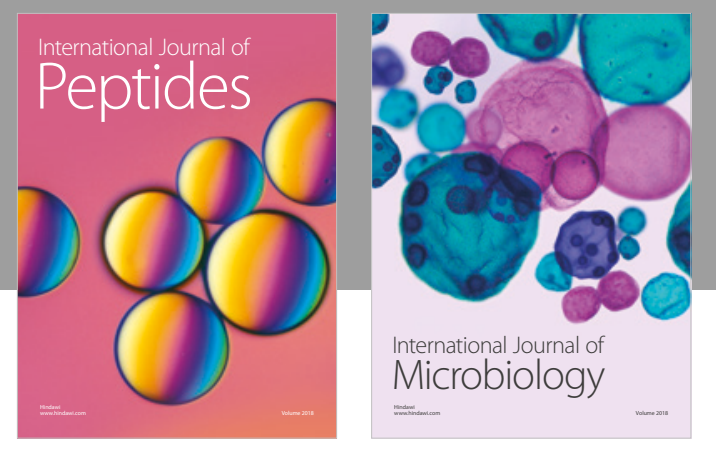

nternational Journal of Microbiology
Journal of
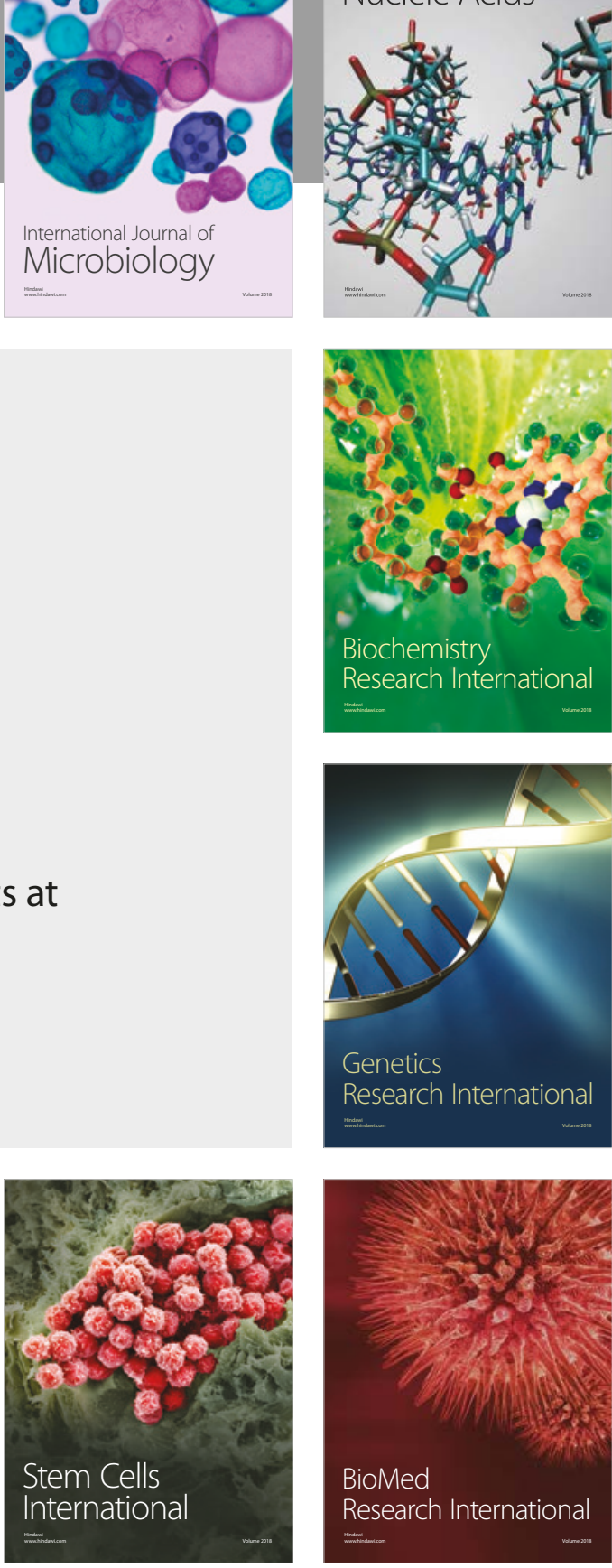
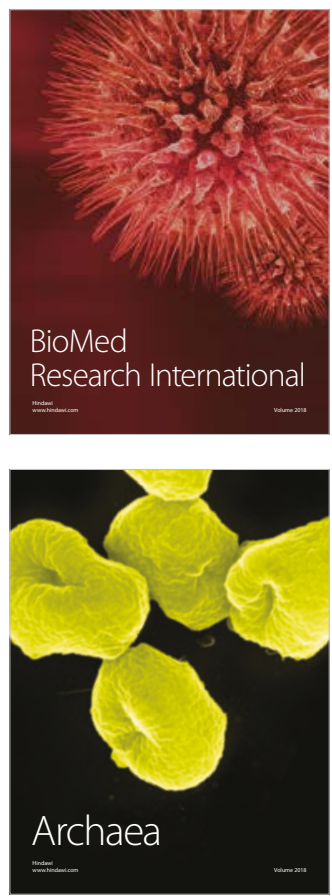